\title{
Leading progress: the role of the chief diversity officer in anesthesiology departments
}

\author{
Gianni R. Lorello, BSc, MD, MSc (Med Ed), CIP, FRCPC, PhD(c) (1)
}

Received: 10 October 2019/Revised: 7 November 2019/Accepted: 11 November 2019/Published online: 18 November 2019

(C) Canadian Anesthesiologists' Society 2019

\section{To the Editor,}

Equity and diversity in medicine is gaining traction, particularly as it relates to women. ${ }^{1,2}$ Despite an increasing proportion of women and other socially-marginalized individuals entering the field of medicine, discrimination at individual and systemic levels create obstacles to academic advancement. This letter intends to inform other academic institutions of the pearls and perils that we have experienced in instituting an equity, diversity, and inclusion (EDI) point person in our department, a position we have named-adopted from the business world-chief diversity officer (CDO).

Diversity and inclusion of thought, as well as people, drive innovation, ${ }^{3}$ and individuals within any department should be representative of the individuals creating the fabric of society that we treat. The Faculty of Medicine at the University of Toronto launched a "We All Belong" campaign (https:// medicine.utoronto.ca/news/why-we-all-belong). As part of the Faculty of Medicine's mandate, creating “excellence through equity" will occur by carrying out EDI initiatives with multiple internal and external stakeholders. The

Electronic supplementary material The online version of this article (https://doi.org/10.1007/s12630-019-01530-5) contains supplementary material, which is available to authorized users.

G. R. Lorello, BSc, MD, MSc (Med Ed), CIP, FRCPC,

$\operatorname{PhD}(\mathrm{c})(\square)$

Department of Anesthesiology and Pain Medicine, Toronto Western Hospital, University Health Network, Toronto, ON, Canada

e-mail: Gianni.Lorello@uhn.ca

Department of Anesthesia, The University of Toronto, Toronto, ON, Canada

The Wilson Centre, Toronto, ON, Canada
Department of Anesthesia at the University of Toronto has taken this mandate to heart and is committed to transformative social change by fostering and nurturing EDI initiatives through the lens of the department's strategic plan (https:// www.anesthesia.utoronto.ca/strategic-plan). As anesthesiologists, we are privileged to treat patients from all walks of life. We endeavor to provide equitable access to empathic care. We also encounter colleagues from multiple sociocultural demographics, with a common goal of improving patient lives. Therefore, it is imperative that we all feel respected and included irrespective of our social identity and/or ethnocultural demographics, not only for our own wellbeing, but also for that of our patients.

As one of the first Canadian Departments of Anesthesia to appoint a CDO, institutionalizing EDI ideology will not be an easy task, and the responsibility does not lie solely on the CDO's shoulders. Both a top-down and a bottom-up approach to EDI implementation will drive compliance and commitment. Working in parallel with the Faculty of Medicine's Office of Inclusion and Diversity, the CDO has a mandate to undertake activities in optimizing and ensuring that our faculty, trainees, and support staff foster a sense of professional wellbeing and quality of life by not being subjected to discrimination, intimidation, bullying, and/or harassment. The CDO will also undertake activities to make the Department of Anesthesia a place where faculty can thrive in their careers, feel valued, and be respected. The CDO is charged with engaging and leading all members within the department in promoting and successfully executing the strategic planning priorities to fruition and bringing an EDI lens to multiple committees.

The Department of Anesthesia at the University of Toronto aims at professionalizing the CDO role by grounding it in theory. The CDO reports to the chair of 
Table Equity, diversity, and inclusion cycle to systematically examine disparities

\begin{tabular}{|c|c|}
\hline $\begin{array}{l}\text { 1) Social construct/identity/ } \\
\text { ethnocultural data audit }{ }^{1}\end{array}$ & Determine the diversity within your department \\
\hline 2) Defining the CDO role & Determine the role and responsibilities \\
\hline $\begin{array}{l}\text { 3) Defining the EDI committee terms } \\
\text { of reference }\end{array}$ & Commitments and requirements you mutually agree upon in order to drive EDI initiatives \\
\hline 4) Report the results to stakeholders ${ }^{1}$ & $\begin{array}{l}\text { An executive council can provide departmental buy-in as well as balance all of the department's requests } \\
\text { to not burden its members with excessive work }\end{array}$ \\
\hline $\begin{array}{l}\text { 5) Determine mechanisms of } \\
\text { disparities }^{1}\end{array}$ & What, how, and why are disparities existing and being perpetuated? \\
\hline $\begin{array}{l}\text { 6) Implement strategies to address } \\
\text { these disparities }{ }^{1}\end{array}$ & $\begin{array}{l}\text { Implement theory-based interventions; } \\
\text { policy creation }\end{array}$ \\
\hline 7) Affirmative action & Implementing policies that support individuals who were previously discriminated against \\
\hline 8) Outcome analysis ${ }^{1}$ & Analyze the data \\
\hline 9) Publish results ${ }^{1}$ & Ensure that the department is aware of the results \\
\hline $\begin{array}{l}\text { 10) Critical reflection (iterative } \\
\text { process) }\end{array}$ & Reflect upon the process rather than just the outcome \\
\hline 11) Conduct interviews to test culture & $\begin{array}{l}\text { Interview socially-marginalized individuals to determine what is going right with the inclusion initiatives } \\
\text { and to determine what can be done to improve the workplace culture }\end{array}$ \\
\hline
\end{tabular}

$\mathrm{CDO}=$ chief diversity officer; $\mathrm{EDI}=$ equity, diversity, and inclusion

the department as well as the vice-chair of clinical affairs and functions in collaboration with the executive council. The CDO has an ex officio role in major committees inside and outside of the Department of Anesthesia within the realms of medical education, research, and administration; serves in an advisory capacity to these committees; and acts as a conduit to EDI resources available at the University of Toronto. The CDO also sits on the Diversity Advisory Council at the Faculty of Medicine and fosters collaborations within and outside of the Faculty of Medicine at the University of Toronto (eFigure, available as Electronic Supplementary Material). We have created a multidisciplinary EDI committee consisting of faculty, trainees, and nurses who act as hospital site point people; everyone has the right to have a voice, to be heard, and to be empowered. We plan on employing and adding to Dr. Julie Silver's \#BeEthical campaign theoretical framework (Table) to better understand and address the disparities that exist and the mechanisms that perpetuate them. ${ }^{4}$

Mentorship for the CDO is essential when implementing a novel role that deals with sensitive issues, spanning structural, legal, cultural, and political boundaries. Mentors inside and outside of the Faculty of Medicine where a director of EDI has been well established is a great place to start. Insights to navigate the system to maximize buy-in at micro-, meso-, and macro-levels as well as expectations in the role can be further delineated. The greatest advice that I received in my new role is that I need to operationalize success for myself in this role-sometimes what matters most is non-measurable.
This letter is intended to provide a roadmap for instituting a CDO at other Departments of Anesthesiology and to depict a plausible organizational structure of how the CDO operates within the departmental structure. The time is right, and we all have an ethical and moral obligation to create diverse and inclusive environments for ourselves and for our patients.

Acknowledgements I would like to thank Dr. Beverley Orser for her tremendous support as Chair of the Department of Anesthesia at the University of Toronto; Ms. Brenda Bui as the backbone of the department as well as her impeccable capacity of balancing administrative duties and support for the CDO; and Dr. Alana M. Flexman for our collaboration and her omnipresent enthusiasm in advancing EDI research.

\section{Conflicts of interest None.}

\section{Funding statement None.}

Editorial responsibility This submission was handled by Dr. Hilary P. Grocott, Editor-in-Chief, Canadian Journal of Anesthesia.

\section{References}

1. McKeen DM, Bryson GL, Lundine J. Underrepresentation of women in Canadian Journal of Anesthesia publications: no surprise-take the pledge! Can J Anesth 2019; 66: 485-90.

2. Flexman AM, Parmar A, Lorello GR. Representation of female authors in the Canadian Journal of Anesthesia: a retrospective analysis of articles between 1954 and 2017. Can J Anesth 2019; 66: 495-502. 
3. Livermore D. Driven by Difference: How Great Companies Fuel Innovation Through Diversity. New York, NY: AMACOM; 2016.

4. Silver JK. \#BeEthical. A Call to Healthcare Leaders: Ending Gender Workforce

5. Disparities is an Ethical Imperative. Available from URL: http:// sheleadshealthcare.com/wp-content/uploads/2018/10/Be_Ethical_ Campaign_101418.pdf (accessed November 2019).
Publisher's Note Springer Nature remains neutral with regard to jurisdictional claims in published maps and institutional affiliations. 